\title{
Palabras de instalación foro "El rol de la ingeniería y de la investigación en ingeniería en el proceso de licenciamiento ambiental”
}

\author{
Opening Words Forum “The role of Engineering and Engineering Science in Environmental Licensing”
}

\author{
Eduardo Behrentz ${ }^{(1)}$ \\ (1) Decano, Facultad de Ingeniería, Universidad de los Andes, Bogotá D.C., Colombia. ebehrent@uniandes.edu.co \\ @behrentz
}

Buenos días para todos. Bienvenidos a la Universidad de los Andes y a este auditorio que lleva el nombre de nuestro fundador. Un saludo a quienes me acompañan en la mesa principal y a quienes van a ser los panelistas de nuestro foro. Un agradecimiento y un saludo al Dr. Pablo Vieira, viceministro de Ambiente y Desarrollo Sostenible, muchas gracias por aceptar la invitación, nos honra con su presencia; al editor invitado de esta edición de la Revista y de este foro, Dr. Carlos Costa, colega, decano amigo, egresado, exministro y amigo de esta casa; al Dr. Barron Henderson, uno de nuestros invitados internacionales; al Dr. Ignacio Toro de CONAMA, también muchas gracias por aceptar la invitación; a dos personas muy representativas del sector: la profesora Ángela Cadena y el Dr. Tirso Quintero, también muy cercano a nuestra Facultad y, a la Dra. Elsa Matilde Escobar de la Fundación Natura, muchas gracias por venir.

Para comenzar diré que como Facultad de Ingeniería estamos tratando, cada vez más, de vender y de ejecutar la idea de que estamos aquí para poner la ingeniería al servicio del país, de manera que el conocimiento y la materia gris que hay en la academia realmente se conviertan en herramientas que ayuden a tomar decisiones. La ingeniería está para resolver problemas y diseñar soluciones. Eso lo tiene muy presente nuestra Facultad. Un muy buen ejemplo de lo anterior es lo que pasa en la Revista de ingeniería y los foros que ella organiza. Para eso estamos: para hacer diagnósticos, diseñar soluciones y promover debates, en este caso particular, en el tema de licenciamiento ambiental.

Aquí hay expertos que ya nos darán un mejor panorama, pero quiero resaltar que la licencia ambiental es, de muchas maneras, la herramienta de gestión ambiental más importante que hay. A través de esta, el Estado se involucra para dejar o no que alguna actividad económica suceda. Además, viene acompañada de temas como los planes de manejo, —que si se hacen bien, si no son solo unos documentos, sino de verdad ejercicios de planificación-, se convierten en el instrumento para mitigar o disminuir por completo el riesgo ambiental.

Así pues, en este foro estamos reuniendo dos elementos fundamentales: la labor tanto de la academia como de la ingeniería y el tema absolutamente coyuntural en nuestro país del licenciamiento ambiental. Los invito entonces a que tengamos un debate muy franco, abierto y apolítico, y hagamos un diagnóstico severo. Lo interesante de estos espacios, como lo conversábamos a la entrada con el Dr. Carlos Costa, es que uno puede empezar a decir 'quiero proponer tal cosa sobre algo que me molesta' y no simplemente seguir criticando algo que no nos gusta. Muchas gracias.

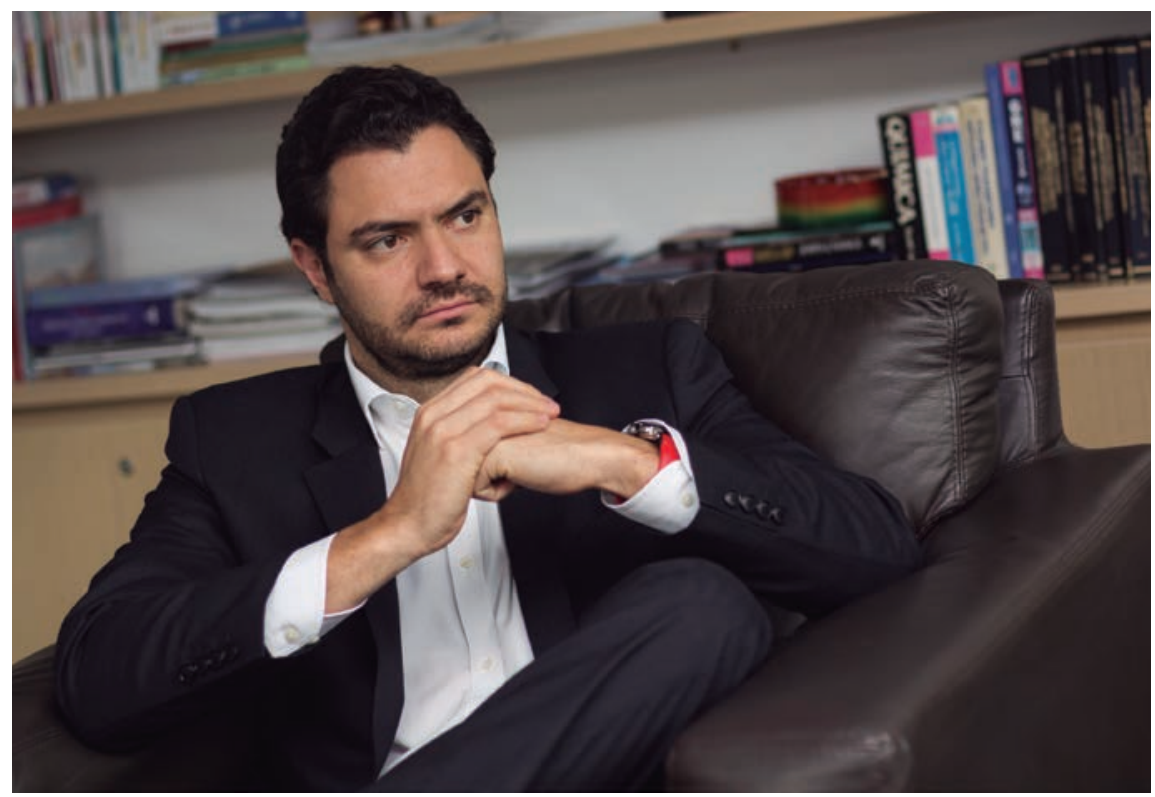

Eduardo Behrentz. Fuente: Archivo Particular, Universidad de los Andes 